\title{
Delineating soil moisture dynamics as affected by tillage in wheat, Rice and establishment methods of rice during intervening period
}

\author{
Rajan Bhatt $^{* 1}$ and S. S. Kukal ${ }^{2}$ \\ ${ }^{1}$ Farm Advisory Service Scheme, TarnTaran, Punjab Agricultural University, Ludhiana-141004 (Punjab), INDIA \\ ${ }^{2}$ Department of Soil Science, Punjab Agricultural University, Ludhiana-141004(Punjab), INDIA \\ *Corresponding author. E-mail: rajansoils@gmail.com \\ Received: December 18, 2014; Revised received: April 22, 2015; Accepted: May 10, 2015
}

\begin{abstract}
Intervening cropping period perhaps the most ignored period, which could be exploited for cultivating the intervening crops which further add to the soil, crop and water productivity and finally livelihood of the farmers of the region. The present investigation was carried out after rice- 2014, to monitor the residual effect of different tillage (wheat), establishment methods and tillage (rice) on the fluctuating behaviour of the soil moisture during intervening period. Our findings suggested that CTW-DSRZT (conventionally tilled wheat and zero till direct seeded rice) plots conserved more moisture than ZTW-DSRZT (zero till wheat and zero till direct seeded rice) plots an exception of CTWDSRCT plots which were almost equally effective in conserving the soil moisture. On an average, soil matric tension (SMT) was reported to be $36 \%$ higher in CTWDSRZT than CTWDSRP plots at $10 \mathrm{~cm}$ soil surface. Further, ZTW-DSRZT plots on an average dried $8 \%$ faster than ZTW-DSRP plots. At $20 \mathrm{~cm}$, DSRZT plots dried $3 \%$ faster than its allied plots while at $30 \mathrm{~cm}$ depth, in DSRP plots, SMT values increased $12 \%$ and $11 \%$ higher under CTW block and ZTW blocks, respectively than its allied plots. SMT readings in all the ZTW plots on an average increased at much more faster rates $(24 \%)$ than CTW plots. The ZT plots had $1.4 \%$ higher water depths than the CT plots. Evaporation losses pragmatic to be higher $(17.2 \%$ and $7.3 \%)$ in ZTW-DSRZT plots as compared to the ZTW -DSRCT and CTW-DSRCT plots which might improve declining crops and water productivity in the region.
\end{abstract}

Keywords: Direct seeded rice, Intervening period, Mechanically transplanted rice, Soil moisture, Zero tilled wheat

\section{INTRODUCTION}

The rice-wheat cropping systems (RWCS) occupies 13.5 million hectares ( $\mathrm{m} \mathrm{ha}$ ) in the Indo-Gangetic Plains (IGP) of India, Bangladesh, Nepal and Pakistan (Gupta and Seth, 2007). In India alone, RW rotation occupies about $10.5 \mathrm{~m}$ ha (Saharawat et al., 2010). Among various challenges in front of sustainable agriculture weeds (Singh et al, 2014, Singh et al, 2015a, b), sequestration of organic carbon (Du et al, 2015, Zheng et al, 2015), puddability of soils (Yao et al., 2015), degraded soil health (Bhatt and Sharma, 2014), declining water tables (Bhatt and Kukal, 2014, Hira et al, 2014, Guan et al, 2015) and declining land, and water productivity (Abdullah, 2014) are the main hurdles. Besides the cropping period, intervening fallow period has tremendous scope to improve overall land productivity but till now, it was ignored as most of studies concentrates entirely on crop stand periods (Bhatt and Kukal, 2014) as during intervening period, scientists busy in analysing the effect of already imposed treatments.

Evaporation (Beff et al., 2013, Singh et al., 2014), rainfall received at soil and plant canopy (Hupet and Vanclooster, 2005) and plant root water uptake (Javaux et al., 2008; Garr'e et al., 2011) are the main factors affecting the soil water retention. Zero tillage (ZT) improved infiltration rate (Nielsen et al., 2005), water retention (Datiri and Lowery, 1991), hydraulic conductivity (Benjamin 1993) under the presence of sufficient straw loads while the scenario might be entirely different in the absence of the mulch load when contradictorily higher water productivities $\left(\mathrm{WP}_{\mathrm{I}}\right.$ and $\mathrm{WP}_{\mathrm{I}+\mathrm{R}}$ ) reported in the $\mathrm{CT}$ plots, mainly because of significantly lower weed biomass (Bhatt and Kukal, 2014). A number of published studied are there in literature, demonstrating effect of tillage on moisture retention during cropping season while almost no study till now covered moisture dynamics during intervening period. Zero tilled plots (with 8.1 percent higher straw load) observed to retain higher temporal volumetric soil moisture as compared to conventionally tilled plots (Bhatt and Kukal, 2014). However, more detailed studies on intervening period after RWCS grown under different RCTs would be quite helpful to come out with an integrated package of rice-wheat establishment methods which helps in practising sustainable agricultural land management (SALM) in the region. Keeping this objective in view, the present study was planned at the end of $2^{\text {nd }}$ RWCS for better understanding of the fluctuation in residual effect of tillage in wheat, establishment methods and tillage in rice on volumetric 
soil moisture retention during the intervening periods after rice.

\section{MATERIALS AND METHODS}

Study site: Experimental site was at the research farm $\left(30^{\circ} 54^{\prime} \mathrm{N}, 75^{\circ} 98^{\prime} \mathrm{E}\right.$, and $247 \mathrm{~m}$ above sea level) of Punjab Agricultural University, Ludhiana, India. The soil was sandy loam, non-saline, near neutral with less than $0.5 \%$ organic carbon. The soil had sub-surface compact layer (Bulk density of $1.74 \mathrm{Mg} \mathrm{m}^{-3}$ in $15-30$ cm layer) (Table 1)

Site history: Our studied site after rice-2014 had already treated with different treatment combination of tillage in wheat, establishment method and tillage in rice from wheat 2012-13 to rice-2014. The treatments consisted of zero tillage and conventional-tillage wheat as the main plots with three replications in randomized block design during wheat 2012-13. The main plot size was $13.8 \mathrm{~m} \times 25.1 \mathrm{~m}$. In the following rice crop, the main plots were divided into split into two subplots for rice establishment viz. direct-seeded rice (DSR) and mechanically transplanted rice (MTR) where the subplots rice tillage treatments were imposed in the split-split design. ZTW-DSRZT plots were under zero tillage from the last two consecutive rice-wheat seasons. Pre-sowing irrigation and rain dates coincide and arrived $17 \mathrm{DAH}$.

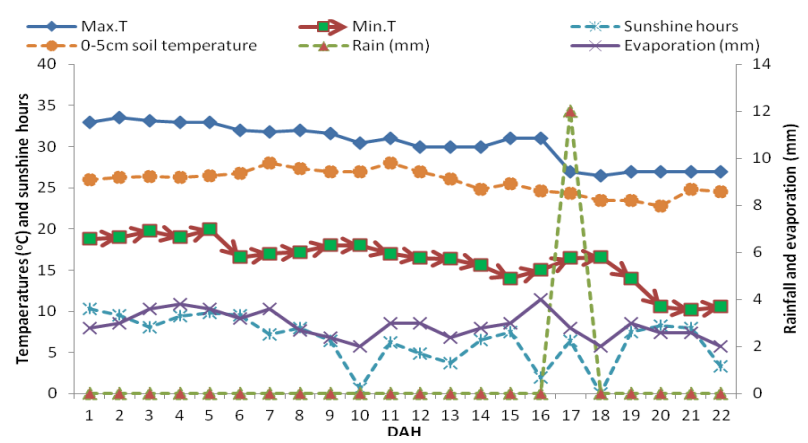

Fig. 1. Different climatic parameters viz. maximum and minimum temperature mean soil 0-5 cm temperature, rainfall $(\mathrm{mm})$, pan-evaporation and sunshine hours variation

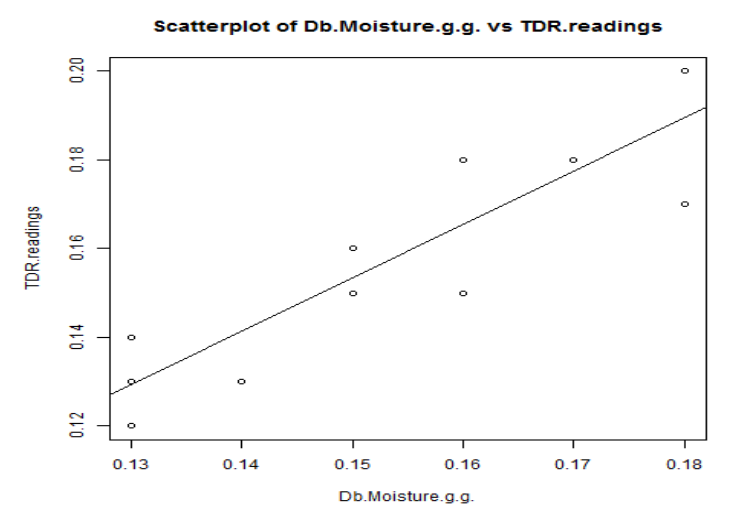

The climate of the region is subtropical with hot, wet summers and cool, dry winters and the different climatic parameters during study period shown in Fig.1. The maximum temperature ranged from 26.5 $33.5^{\circ} \mathrm{C}$ while minimum temperature varied from 10.2 19.8 while only single rainy day with a total of $12 \mathrm{~mm}$ of rain observed which significantly decreased the sunshine hours while a total of $63.2 \mathrm{~mm}$ of pan evaporation and 143 total sunshine hours received during studied period (Fig. 1). Soil temperature particularly of surface soil is quite important in evaporation studies as it causes the phase change of soil water from liquid to vapour phase (Morau and Rusu, 2012; Bhatt and Khera, 2006; Balwinder Singh et al., 2011). Digital soil thermometers were used for recording daily soil surface temperature in different plots established from upper 2 inch of differently treated plots.

For present study, TDR with $7.5 \mathrm{~cm}$ probes was used to study temporal fluctuations. Before using, TDR was calibrated by plotting it's different readings with the different readings of product of bulk density and gravimetric moisture content in different plots using STAR (Statistical Tool for Agricultural Research) package and $r^{2}$ comes out to be 0.75 depicting good relationship in between both plotted parameters (Fig. 2). The mini-lysimeters are quite effective in understanding fluctuating behaviour of evaporation in divergently tilled plots. PVC pipes which were of 8 inch length and with 4.0 inches diameter were used for preparing lysimeters, filled with hammer and pulled out using chain pulley arrangement, an end cap fixed on one side and then placed inside the outer pipe of bigger diameter which itself was already fixed in the sampled plot. Daily mini-lysimeters were weighted using digital balance for measuring grams of water evaporated in a particular tillage treatment.

Electronic tensiometers depicting soil matric suction variation in a particular plot under a particular treatment (Kukal et al., 2004, Bhatt et al., 2013). Tensiometers were installed at different depths viz. 10, 20 and $30 \mathrm{~cm}$ in the soil profile during the intervening

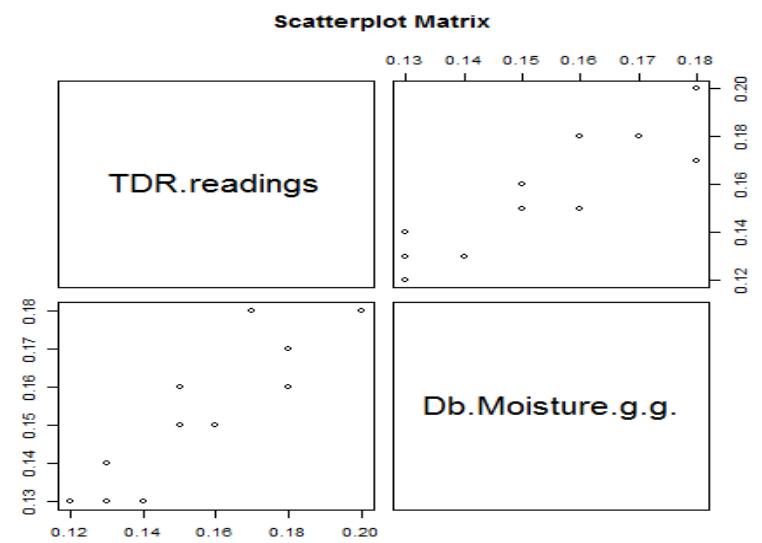

Fig. 2. Calibration of TDR $\left(r^{2}=0.75\right)$ showed good relation between product of bulk density and gravimetric moisture content and TDR readings using STAR software during 2014. 
Table 1. Basic physico-chemical properties of the studied site.

\begin{tabular}{|c|c|c|c|c|c|c|c|c|c|}
\hline \multirow{2}{*}{$\begin{array}{l}\text { Depth } \\
\text { (cm) }\end{array}$} & \multirow{2}{*}{$\begin{array}{l}\text { Sand } \\
(\%)\end{array}$} & \multirow{2}{*}{$\begin{array}{l}\text { Clay } \\
(\%)\end{array}$} & \multirow{2}{*}{$\begin{array}{l}\text { pH } \\
(2: 1)\end{array}$} & \multirow{2}{*}{$\begin{array}{l}\text { EC } \\
(2: 1)\end{array}$} & \multirow{2}{*}{$\begin{array}{l}\text { O.C } \\
(\%)\end{array}$} & \multicolumn{3}{|c|}{ Available nutrients( $\left.\mathrm{kg} \mathrm{ha}^{-1}\right)$} & \multirow[t]{2}{*}{$\mathrm{Db}\left(\mathrm{Mg} \mathrm{m}^{-3}\right)$} \\
\hline & & & & & & $\mathbf{N}$ & $\mathbf{P}$ & $\mathbf{K}$ & \\
\hline $0-15$ & 64.7 & 11.3 & 7.26 & 0.25 & 0.45 & 341.2 & 15.2 & 250.8 & 1.66 \\
\hline $15-30$ & 65.9 & 11.3 & 7.23 & 0.31 & 0.44 & 332.8 & 14.2 & 218.6 & 1.74 \\
\hline $30-60$ & 66.8 & 12.6 & 7.31 & 0.32 & 0.35 & -- & -- & -- & 1.59 \\
\hline $60-90$ & 67.6 & 12.7 & 7.18 & 0.26 & 0.37 & -- & -- & -- & 1.63 \\
\hline $90-120$ & 68.2 & 12.3 & 7.01 & 0.34 & 0.34 & -- & -- & -- & 1.57 \\
\hline $120-150$ & 68.8 & 11.9 & 7.08 & 0.33 & 0.32 & -- & -- & -- & 1.61 \\
\hline
\end{tabular}

period. Digital SPEC readings were recorded daily to understand the fluctuating behaviour of soil matric tension within differently treated plots.

Analysis of daily recorded data from above instruments in differently tilled plots helped in identifying a particular combination of tillage in wheat, establishment method and tillage in rice treatment which

retained higher sum of volumetric moisture content which is important for intervening crops which further improved the soil health, water productivity and finally livelihood of poor farmers in the region.

\section{RESULTS AND DISCUSSION}

Weather conditions: All the weather parameters data
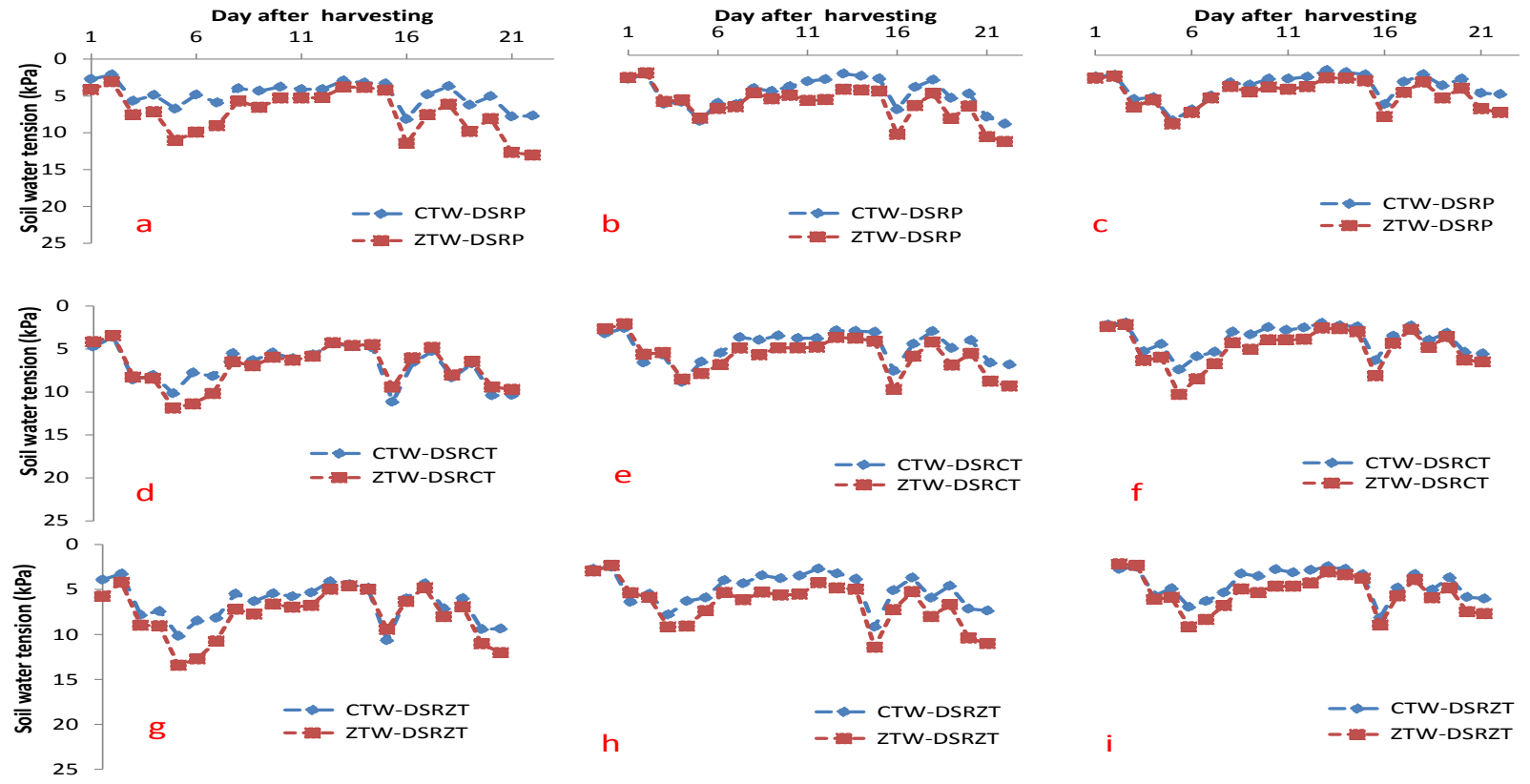

Fig. 3. Temporal fluctuations in soil matric potential in CTWDSRP vs ZTWDSRP from 10-30 cm soil depth (a-c), in CTWDSRCT VS ZTWDSRCT from 10-30 cm soil depth (d-e) and CTWDSRZT vs ZTWDSRZT from 10-30 cm soil depth (g-i)

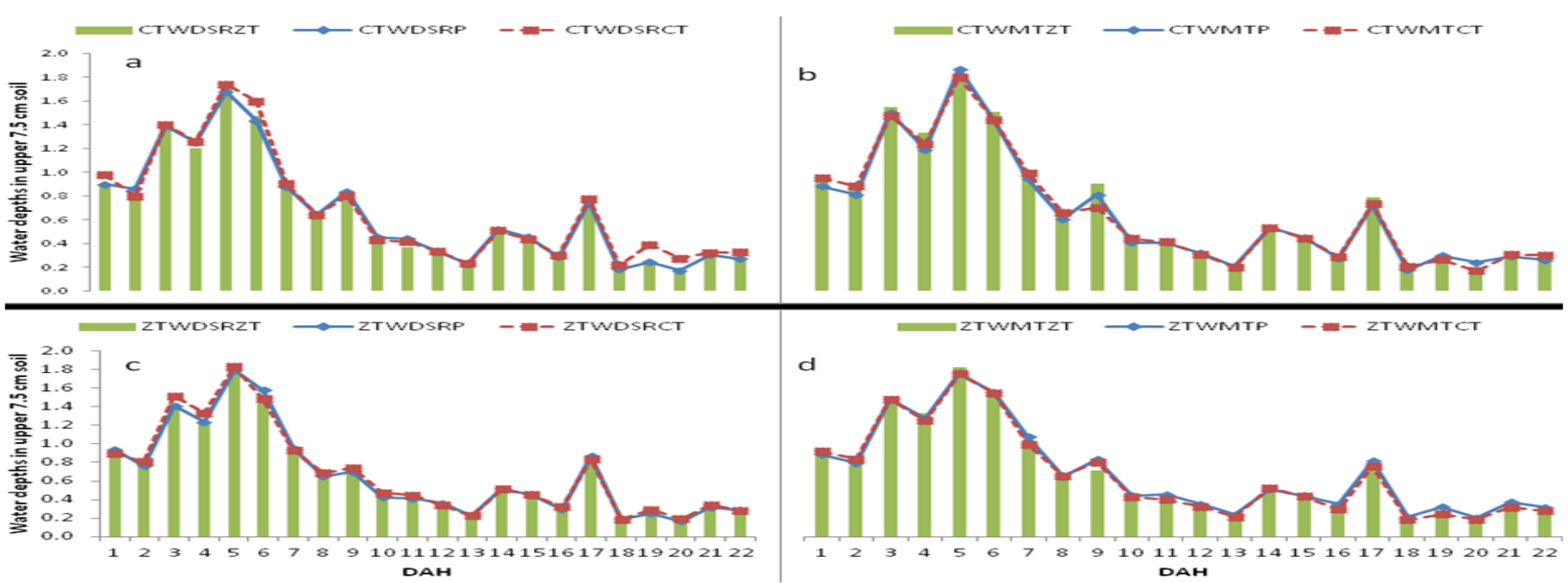

Fig. 4. Water depth present in $7.5 \mathrm{~cm}$ of surface plots which were under differential tillage wheat and establishment methods and tillage in rice treatments from two years after rice 2014 


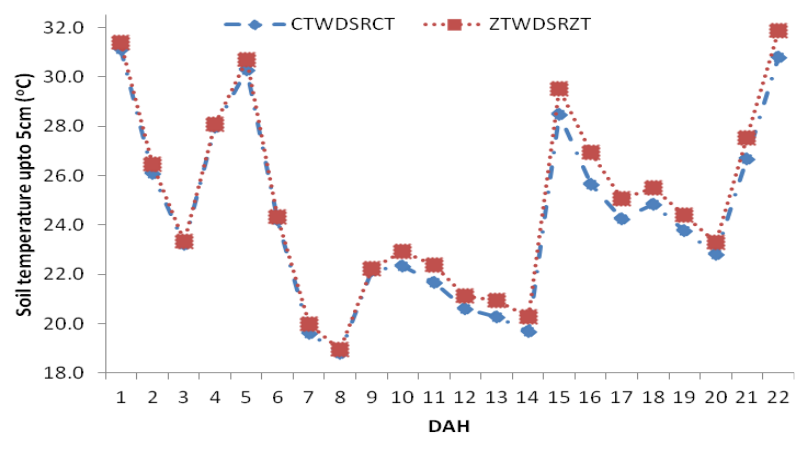

Fig. 5. Surface soil temperature as affected by tillage in

viz. maximum and minimum temperature, sunshine hours, pan-evaporation collected from the meteorological observatory. However, the rain data obtained from the rain gauge installed at the experimental site immediately after harvesting of rice-2014. From a general overview, it appears that all the parameters viz. maximum and minimum temperature, sunshine hour's decreases in magnitude which also appeared in the evaporation trends and a rain of $12 \mathrm{~mm}$ received on 17 DAH after rice 2014 (Fig. 1).

Soil matric tension: Soil matric tension (SMT) readings revealed that permanent $\mathrm{ZT}$ plots dried out faster than plots which were under CT from the last four seasons irrespective of soil depth and tillage in rice (Fig 3, a-i) which was mainly because of no mulch load, continuous supply of water from deeper layers due to continuity of soil pores and recorded higher soil temperature throughout intervening period (Fig. 5) while in CT plots, the continuity of soil pores broken by tillage operations which further results in lesser supply of water to evaporating site from the deeper layers and finally resulted in lesser evaporation. However, magnitude of drying (more particularly in CTW plots) decreases as studied soil depth increases. At all the soil depths viz. 10, 20 and $30 \mathrm{~cm}$ soil depths, SMT values go on increasing as the days after harvesting increases. On an average, SMT reported to be $36 \%$ higher in CTWDSRZT than CTWDSRP plots at $10 \mathrm{~cm}$ soil surface while at 20 and $30 \mathrm{~cm}$ SMT reported to be varied at almost same pace in all the plots of DSRP, DSRCT and DSRZT plots (Fig. 3). Some rains of lower magnitudes were there but having no significant effect on SMT. However, in zero tilled wheat plots, DSRZT plots on an average dried $8 \%$ faster than DSRP plots which in turn dried out almost at same pace as that of DSRCT while at $20 \mathrm{~cm}$, DSRZT plots dried 3\% faster than it's allied plots while at $30 \mathrm{~cm}$ depth, in DSRP plots, SMT values increased $12 \%$ and $11 \%$ higher under CTW block and ZTW blocks, respectively than its allied plots. SMT readings in all the ZTW plots on an average increased at much more faster rates $(24 \%)$ than CT plots at all the soil depths indicating greater and prolonged retention of soil moisture in later plots (Fig. 3). However, in same

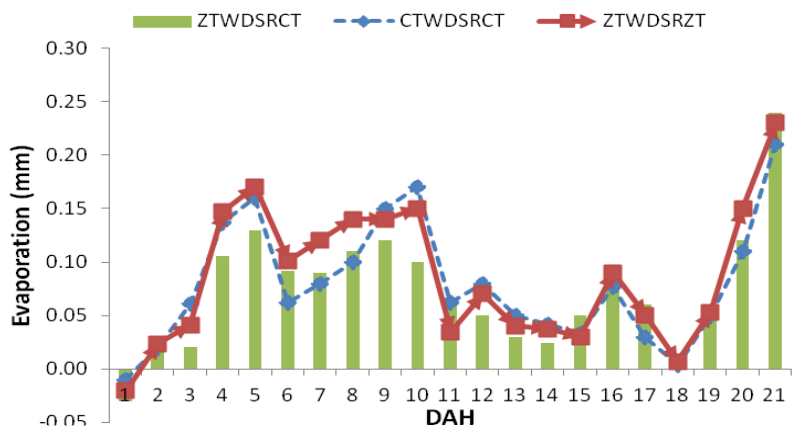

Fig. 6. Daily evaporation trends (a) and total loss of evaporative water (b) under different treatments during interven-

experiment after rice 2013, higher moisture in ZT plots reported and that may be because of retained straw load of $2 \mathrm{t} \mathrm{ha}^{-1}$ straw loads (Bhatt and Kukal, 2014).

Volumetric water content: All the harvested plots retained almost equal water depths in the top $7.5 \mathrm{~cm}$ irrespective of the establishment method and tillage in rice. However, these values decreased 3.2\% higher in DSR plots as compared to the MT plots. Time domain reflectrometer (TDR) indicated that conventionally tilled plots retained $6.0 \%$ higher quantity of moisture content than zero tilled plots during intervening period because of more favourable conditions for evaporation and absence of straw loads in ZT plots which might have resulted in easy diffusal of water vapour out of soil (Fig. 4). Recorded higher soil temperature in upper $5 \mathrm{~cm}$ of soil surface in ZT plots $(2.2 \%$ higher $)$ also strengthen the higher moisture loss due to better availability of energy for phase change from liquid to gases form in ZT plots as compared to the CT plots (Fig 5).

Soil temperature: Permanent zero tilled plots (ZTWDSRZT plots) evaporate faster than permanent CT plots (CTW-DSRCT plots) while ZTWDSRCT plots reported to had lowest evaporation throughout the intervening periods (Fig 6). Total evaporation throughout studied period in plots under permanent zero tillage was 7.34 and $17.2 \%$ higher than CTWDSRCT and ZTWDSRCT plots respectively (Fig. 6). ZTWDSRZT plots already recorded with $2.2 \%$ higher soil temperature (Fig. 5) might be responsible for this. Further, SMT readings jumped quickly in the ZT plots than that in CT plots (Fig. 3) depicting quicker drying of soil at different depths in the former plots for which continuity of soil pores might be responsible while in the CT plots, the continuity of the soil pores disturbed by tillage which restricted supply of moisture from the deeper layers to the evaporation site. At $18 \mathrm{DAH}$, the evaporation magnitude comes down to almost zero in all the treatments and recognized reason is the pre-sowing irrigation and rain which occurred on same day (17 DAH).

\section{Conclusion}

During intervening periods, ZTWDSRCT retained 
higher moisture content (though significantly at par with plots under conventional tillage from the last four season's viz. CTWDSRCT) with recorded lowest values for the plots which were under zero tillage from the last four season's viz. ZTWDSRZT. Further such investigations, during intervening periods in texturally divergent soils under different agro-climatic regions need to be carried out for more intervening periods for better understanding of the residual effects of tillage in wheat and establishment methods and tillage in rice on the soil moisture retention during intervening periods in the rice-wheat cropping system of the region.

\section{ACKNOWLEDGEMENT}

Authors are extremely thankful to Department of Soil Science, Punjab Agricultural University, Ludhiana, India, for the providing necessary facilities to carry out this study.

\section{REFERENCES}

Abdullah, A.S. (2014). Minimum tillage and residue management increase soil water content, soil organic matter and canola seed yield and seed oil content in the semiarid areas of Northern Iraq. Soil Till Res., 144: $150-155$.

Beff, L., Unther, T. G. B., Vandoorne, C.V. and Javaux, M. (2013). Three-dimensional monitoring of soil water content in a maize field using Electrical Resistivity Tomography. Hydrology Earth System Sci., 17: 595-609.

Benjamin, J. G. (1993). Tillage effects on near-surface soil hydraulic properties. Soil Till Res., 26 (4): 277-288.

Bhatt, R. and Khera, K.L. (2006) Effect of tillage and mode of straw mulch application on soil erosion in the submontaneous tract of Punjab, India. Soil Till Res., $88: 107-115$.

Bhatt, R. and Kukal, S.S. (2014). Moisture retention trends during the intervening period of differently established rice-wheat cropping pattern in sandy loam soil. Inter $J$. Farm Sci., 4(2): 7-14

Datiri, B.S. and Lowery, B. (1991). Effects of conservation tillage on hydraulic properties of a Griswold silt loam soil. Soil Till Res., 21(3-4): 257-271.

Du, Z., Ren, T., Huc, C. and Zhang, Q. (2015). Transition from intensive tillage to no-till enhances carbon sequestration in microaggregates of surface soil in the North China Plain. Soil Till Res., 146: 26-31.

Garr'e, S., Javaux, M., Vanderborght, J., Pag`es, L. and Vereecken, H. (2011). Three-dimensional electrical resistivity tomography to monitor root zone water dynamics. Vadose Zone J., 10: 412-424.

Guan, D., Zhang, Y., Mahdi, M., Kaisi, A., Wang, Q., Zhang, M. and Li, Z. (2015). Tillage practices effect on root distribution and water use efficiency of winter wheat under rain-fed condition in the North China Plain. Soil Till Res., 146: 286-295.

Hupet, F. and Vanclooster, M. (2005). Micro-variability of hydrological processes at the maize row scale: implications for soil water content measurements and evapo-transpiration estimates. J Hydro., 303: $247-270$

Javaux, M., Schroder, T., Vanderborght, J. and Vereecken, H. (2008). Use of a three-dimensional detailed modeling approach for predicting root water uptake. Vadose Zone J., 7: 1079-1088.

Kukal, S.S. and Sidhu, A.S. (2004). Percolation losses of water in relation to pre-puddling tillage and puddling intensity in a puddled sandy loam rice (Oryza sativa) field. Soil Till Res., 78 (1): 1-8.

Ladha, J.K., Hill, J.E., Duxbury, J.M., Gupta, R.K. and Buresh, R. J. (2003b). Improving the productivity and sustainability of rice-wheat systems: issues and impacts. ASA Spec. Publ. 65. ASA, CSSA and SSA, Madison, WI, pp. 1-231.

Nielsen, D.C., Unger, P. and Miller, P. R. (2005). Efficient water use in dryland cropping systems in the Great Plains. Agronomy J., 97: 364-372.

Singh, B., Eberbach, P.L. and Humphreys, E. (2014). Simulation of the evaporation of soil water beneath a wheat crop canopy. Agri Water Manag., 135: 19-26.

Singh, B., Humphreys, E., Eberbach, P.L., Katupitiya, A., Singh, Y. and Kukal, S.S. (2011). Growth, yield and water productivity of zero till wheat as affected by rice straw mulch and irrigation schedule. Field Crop Res., 121: 209-225.

Singh, M., Bhullar, M. S. and Chauhan, B.S. (2014). The critical period for weed control in dry-seeded rice. Crop Protec., 66: 80-85.

Singh, M., Bhullar, M. S. and Chauhan, B.S. (2015) Influence of tillage, cover cropping, and herbicides on weeds and productivity of dry direct seeded rice. Soil Till Res., 147: 39-49.

Singh, M., Bhullar, M. S. and Chauhan, B.S. (2015). Seed bank dynamics and emergence pattern of weeds as affected by tillage systems in dry direct-seeded rice. Crop Prot., 67: 168-177.

Zheng, L., Wu, W., Wei, W. and Hu, K. (2015). Effects of straw return and regional factors on spatio-temporal variability of soil organic matter in a high-yielding area of northern China. Soil Till Res., 145: 78-86. 